\title{
Education individualization by means of artificial neural networks
}

\author{
Nataliia Valko $^{1, *}$, and Viacheslav Osadchyi ${ }^{2}$ \\ ${ }^{1}$ Kherson State University, 27 Universytetska Str., Kherson, 73000, Ukraine \\ ${ }^{2}$ Bogdan Khmelnitsky Melitopol State Pedagogical University, 20 Hetmanska Str., Melitopol, 72300, Ukraine
}

\begin{abstract}
This paper examines the issues related to the implementation of an educational process based on modern information technologies use. The main purpose of it is to achieve a significant level of individualization of the educational process, taking into account the individual characteristics and capabilities of each participant of the process. The implementation of the approach became possible at using elements of the theory of artificial neural networks in the educational process. Based on the network, it is possible to build a model of the educational process; it will significantly increase the control of the teacher on the educational process. Moreover, this network can adapt to a specific education task, the individual characteristics of the student and teacher. The mathematical model of the educational process using modern information technologies and neural networks is constructed. Their use is based on the developed criteria of successful execution of various stages of the educational process. Such criteria are designed for both the student and the teacher. The characteristic of participant's activity of the educational process is considered in the work. A numerical interpretation of this concept is proposed.
\end{abstract}

\section{Introduction}

Modern pedagogical technologies rely on the latest educational informational means. In particular, computer and robotics training requires a teacher and student to use basic knowledge in Physics, Mathematics, Programming, and Engineering. The training system of future teachers of natural and mathematical disciplines aims to develop the skills of engineering thinking, the use of technologies to solve problems, to familiarize them with the basic concepts and information in mathematical modeling and object construction.

The education process is a communication system, and it can be described as an artificial neural network of influences. It has a function with many variables at the input and a fixed result at the output. For such a representation it is necessary to formalize the educational process in a certain way, to construct its mathematical model, which will take into account all the steps necessary to achieve the purpose of the educational study. Recently, there has been a significant increase in using elements of the theory of artificial neural networks in the educational process. This interest is specified by the ability of such networks to respond quickly to changing conditions of the education process, adapt to these changes, analyze them and find the optimal parameters.

Modern educational needs are search, development and application of innovative models of organization of the educational process $[1,2,3]$. In this regard, there is an urgent need to introduce the elements of education in the teacher training system, to introduce students to the elements of programming, design, mathematical modeling, and more. The system, in this case, means the set of elements that interact and communicate with each other and create the appropriate integrity, organized to achieve one or more goals.

Questions of constructing models of the training system by means of neural networks were analyzed by O. D. Humennyi [6], A. E. Kiv [14], V. S. Kruglyk [2], O. M. Markova [12], V. V. Osadchyi [16], V. N. Soloviev [15], R. V. Streltsov [5], I. O. Teplytskyi [13] and others. Possibilities of neural networks as a component of students' distance education system were considered by P. I. Fedoruk [4]. The artificial intelligence in the system is responsible for knowledge control. It allows to determine the level of educational achievements of students and to model the personal education trajectory, selecting the appropriate training modules. R. V. Streltsov and L. V. Slavinskaya [5] developed a computer-based education system using neural networks to optimize interaction between all participants in the education process. O. D. Humennyi proposed the model for the use of the Kosco neural network for the concept of designing Smart complexes of subjects [6]. In their works V. V. Osadchyi, V. S. Kruglyk and D. O. Bukreev use a neural network training mechanism to determine the likelihood of entrants to higher education institutions [7, 17]. In [8], the dependences of student performance (good and excellent grades) on the number of control nodes per semester in various academic subjects (analytical

* Corresponding author: valko@ksu.ks.ua 
geometry, mathematical analysis, and physics) are constructed. In [9], a model of optimal quantitatively grounded system of training of future physics teachers based on the relative importance of the education goals. However, little attention has been paid to constructing a neural network model based on numerical characteristics of the control, analysis, and correction to individualize of education.

The study of disciplines of the natural mathematical cycle, raises the question of strengthening the individual approach in the study of these disciplines, taking into account the individual characteristics of the student and the teacher. However, enhancing of education individualization leads to a significant increase in educational work, sometimes poorly linked to the education content. The application of artificial neural networks to the educational process, which, combined with modern computer technology, can significantly simplify this process and enhancing the level of education individualization. The use of artificial neural networks in the education process implies, first of all, that the whole education process, or at least its main elements, should be presented in digital form. For the disciplines of the natural mathematical cycle it is a feasible task. However, the educational process of a large number of disciplines is poorly formalized, and sometimes it is not at all conceivable as a sequence of particular pedagogical influences that can be measured or estimate by numerical values. So, we propose a method of elementary tasks, which, in our opinion, can greatly facilitate the formalization of the educational process of a considerable number of disciplines. Moreover, using this method, it becomes possible to apply the elements of artificial neural network theory in the educational process. The main purpose of this work is to establish numerical characteristics that are amenable to algorithmization, control, analysis and correction by means of neural networks, and provide a high level of individualization of training.

\section{The method of elementary tasks}

The elementary tasks method is based on the concept of an elementary task. Here is a description of this concept.

Let's consider educational (pedagogical, educational and other) task. Let us denote this task by $Z$. Suppose that the task $Z$ can be fulfilled only if we consistently perform $k$ simpler tasks $z_{i}(i=1, \ldots, k)$, with which performer (student, educator, teacher, etc.) is familiar, which are provided by the prior training and can be successful completed. Suppose that it is possible to set (measure) the execution time of each of the tasks $z_{i}$, and as a result of the execution it is possible to set: each of the tasks $z_{i}$ is completed or not completed. If all the above conditions are fulfilled, then the problem $z_{i}$ $(i=1, \ldots, k)$ will be called elementary problems for task $Z$.

The above definition of an elementary task is, by its nature, reminiscent of the definition of the classical probability of a random event through a complete group of elementary events. This similarity makes it possible to transfer many properties of classical probability in case of elementary problems. However, there are some differences in these concepts. In particular, all elementary events are equally likely, but for elementary tasks, as shown below, it is not always performed. In addition, the elementary events are insignificant in the order in which they are performed, but the elementary tasks must be performed in a certain order, otherwise the task $Z$ may not be completed.

Each of the elementary tasks can be assigned its "weight" for the task $Z$. If we denote by $T(Z)$ the time required for its successful completion and by $T\left(z_{i}\right)$ the time required for the successful completion of the elementary task $z_{i}(i=1, \ldots, k)$, then "weight" of the elementary problem $z_{i}$ for task $Z$ we will call the number

$$
\frac{T\left(z_{i}\right)}{T(Z)} \text {. }
$$

Performing task $Z$, the condition of its timely execution must be fulfilled:

$$
T(Z)=\sum_{i=1}^{k} T\left(z_{i}\right)
$$

Each of the elementary tasks $z_{i}$ for task $Z$ can be characterized by another parameter, the value of which is set only after its execution - "success" of execution. Although it is assumed that an elementary task is familiar to the performer and he or she must successfully complete it, however, for a number of reasons, objective and subjective, the elementary task may be unfulfilled or incorrectly performed. It will affect the fulfillment of the task $Z$. Let us denote by $U(Z)$ the result of completing of the task $Z$, and by $U\left(z_{i}\right)$, respectively, the result of completing the elementary task $z_{i}$. The $U$ function accepts only two values -0 if the corresponding task is not completed, or 1 if it is successfully completed. Now it is necessary to set the numerical condition for completing the task $Z$. To do this, each of the elementary $\operatorname{tasks} Z_{i}(i=1, \ldots, k)$ must be fulfilled:

$$
\prod_{i=1}^{k} U\left(z_{i}\right)=1
$$

Thus, successful completion of task $Z$ requires the fulfillment of both conditions: successful and timely completion of all its elementary tasks.

Considering that the fulfillment of task $Z$ always begins with the fulfillment of the elementary task $z_{1}$, then the following can be a condition for the consistent execution of all elementary tasks:

$$
U\left(z_{1}\right)=1, U\left(z_{i}\right) \cdot U\left(z_{i+1}\right)=1(i=1, \ldots, k-1),
$$

They should be checked after completing each of the elementary tasks. Unless individual elementary tasks require the required sequence of execution, they should be considered as separate tasks.

Therefore, the realization of fulfillment of all three of conditions: timeliness, success and sequence of completion of all elementary tasks for task $Z$ are necessary and sufficient conditions for successful 
completion of task $Z$. Now these conditions can be written in analytical form:

$$
\left\{\begin{array}{c}
T(Z)=\sum_{i=1}^{k} T\left(z_{i}\right) \\
\prod_{i=1}^{k} U\left(z_{i}\right)=1 \\
U\left(z_{1}\right)=1, U\left(z_{i}\right) \cdot U\left(z_{i+1}\right)=1(i=1, \ldots, k-1)
\end{array}\right.
$$

These conditions can form the basis of a mathematical model of the educational process. It should be noted that a task that is successfully completed can later be used as an elementary for a more complex task. It is clear that the time allotted for the task must have some tolerable (insignificant compared to the scheduled time) deviations, both upward and downward. These deviations should be taken into account at constructing the mathematical model of a particular education process.

\section{Activity modeling and evaluation}

In the previous paragraph, the numerical criteria for the successful completion of a specific training task were formulated. It is successful implementation depends on the performer's activity. This is a characteristic that is quite difficult to model. However, the elementary tasks method makes it possible to estimate it by setting the corresponding numerical value. To do this, we introduce the following notations.

Suppose that in order to successfully completed task $Z$, you must execute $N$ elementary tasks. Denote by $N^{(+)}$ the number of elementary tasks that have been successfully completed and by $N^{(-)}$- the number of elementary tasks that have not been completed. The equality must be executed:

$$
N=N^{(+)}+N^{(-)}
$$

that is, every elementary task is either completed or not completed.

Activity $A(Z)$ of the performer during the execution of the main task $Z$, we will define as the ratio of the number of completed elementary tasks to the number of all elementary tasks:

$$
A(Z)=\frac{N^{(+)}}{N} .
$$

This definition of the activity of the performer is, in fact, analogous to the definition of the classical probability of a random event equal to the ratio of the number of elementary random events contributing to the occurrence of this random event to the total number of elementary random events. It makes up a complete group of elementary events. Indeed, activity, like classical probability, satisfies the inequalities:

$$
0 \leq A(Z) \leq 1
$$

In addition, if none of the elementary tasks is fulfilled, then the equality is satisfied: $A(Z)=0$, but if the task is completed successfully, then the equality is satisfied:

$$
A(Z)=1 \text {. }
$$

It should be noted that the success execution of the elementary tasks and the sequence of their completion should not affect the performer's activity. Violation of this sequence must be taken into account after completing the entire task $Z$, in the analysis and evaluation of the work of the performer. This requirement can be formulated as a continuity of the education process.

So far, we have only considered one task performer. However, more than one performer can participate in the education process, and they can perform both joint tasks and individual tasks. The model of performing a single task by one performer was discussed above. Suppose now that task $Z$, with elementary tasks $z_{i}(i=1, \ldots, N)$, is performed by $m$ executors. Denote by $N^{(+)}$the number of successfully completed elementary tasks, and by $N_{j}^{(+)}(j=1, \ldots, m)$ denote the number of elementary tasks successfully completed by the $j$-th performer. In this case, the following conditions must be observed:

1) Each elementary task is performed by only one performer, and only once, the equality must be fulfilled:

$$
N^{(+)}=\sum_{j=1}^{m} N_{j}^{(+)} \text {. }
$$

2) It should not be more executors than elementary tasks $z_{i}(i=1, \ldots, N)$ for task $Z$, that is, the inequality: $m \leq N$ must be satisfied.

The described method of elementary tasks gives an opportunity to evaluate the work of the performer on the fulfillment of task $Z$. In our opinion, the performer can get a positive assessment even if this task is not successfully completed. The determinant should be the activity of the performer, as performance evaluation should encourage the performer and show progress in education. By the appropriate positive factor $\gamma$ (multiplier of evaluation) can be set the mark $O_{v}(Z)$ of the work of the executor of task $Z$, by pre-scaling this factor according to the established rating system. For example, if all elementary tasks have approximately the same weight, then you can use the following value of the evaluation of task $Z$ :

$$
O_{v}(Z)=\gamma A(Z)
$$

Otherwise, elementary tasks differ significantly in weight, then depending on the weight of each elementary task and the result of its execution, it is possible to establish another equality for evaluating of the execution of elementary task $z_{i}$ For example, for the case of a 100point evaluating system, we can put: $\gamma=100$. Then, to evaluate the successful and timely completion of the elementary task $z_{i}$ for the task $Z$ can be taken the number:

$$
O_{v}\left(z_{i}\right)=\gamma \frac{T\left(z_{i}\right)}{T(Z)} U\left(z_{i}\right)=100 \frac{T\left(z_{i}\right)}{T(Z)} U\left(z_{i}\right) .
$$


The total score for task $Z$ will be formed as the sum of the marks of each elementary task $z_{i}$ for task $Z$ :

$$
\begin{gathered}
O_{v}(Z)=\frac{\gamma}{T(Z)} \sum_{i=1}^{k} T\left(z_{i}\right) U\left(z_{i}\right) \\
=\frac{100}{T(Z)} \sum_{i=1}^{k} T\left(z_{i}\right) U\left(z_{i}\right) .
\end{gathered}
$$

From this equality it follows that with the successful and timely completion of all elementary tasks, the performer will receive a score of 100 points. If, however, one of the elementary tasks is not executed, then it does not bring a positive assessment to the overall assessment. Thus, the performance evaluation of the performer is directly related to his/her activity during task $Z$ execution.

It is clear the actual execution time of a single elementary task, or the entire task, will be different from the planned values. In this case, it is possible to adjust the estimate by a value proportional to the tolerance of the corresponding parameter - to increase it if the actual execution time is less than planned, or to decrease otherwise. At the same time, it is necessary to ensure that the actual time of execution of the elementary task and the whole task does not exceed the set allowable values of deviation from the planned values of the corresponding parameter.

Let's consider this case. We introduce additional notations. Denote by $t\left(z_{i}\right)$ and $t(Z)$, respectively, the actual execution time of the elementary task $z_{i}$ and the entire task $Z$. In addition, denote by $\Delta T\left(z_{i}\right)$ and $\Delta T(Z)$ absolute value of the tolerable deviation of the actual value from the planned for corresponding parameter.

The considered values must satisfy the following conditions:

- actual time of execution of task $Z$ should not differ from the planned more than the planned deviation of this parameter:

$$
|T(Z)-t(Z)| \leq \Delta T(Z)
$$

- the actual execution time of the elementary task $z_{i}$ should not differ from the planned more than the planned deviation of this parameter:

$$
\left|T\left(z_{i}\right)-t\left(z_{i}\right)\right| \leq \Delta T\left(z_{i}\right) ;
$$

- increased time for the execution of some elementary task reduces the time for the execution of other elementary tasks:

$$
T(Z)+\Delta T(Z) \geq \sum_{i=1}^{k}\left(T\left(z_{i}\right)+\Delta T\left(z_{i}\right)\right) ;
$$

- reduced time for the execution of some elementary task increases the time for the execution of other elementary tasks:

$$
T(Z)-\Delta T(Z) \leq \sum_{i=1}^{k}\left(T\left(z_{i}\right)-\Delta T\left(z_{i}\right)\right) .
$$

At execution of the above limitations, the planned evaluation for execution of 0 the elementary task $Z_{i}$ can be changed by:

$$
\gamma \frac{T\left(z_{i}\right)-t\left(z_{i}\right)}{T(Z)}
$$

The final evaluation for completing the elementary task $z_{i}$, in this case, will be calculated by the formula:

$$
\begin{aligned}
O_{v}\left(z_{i}\right)= & \gamma\left(\frac{T\left(z_{i}\right)}{T(Z)}+\frac{T\left(z_{i}\right)-t\left(z_{i}\right)}{T(Z)}\right) U\left(z_{i}\right) \\
& =\gamma \frac{2 T\left(z_{i}\right)-t\left(z_{i}\right)}{T(Z)} U\left(z_{i}\right) .
\end{aligned}
$$

Thus, if the time for the elementary task $Z_{i}$ execution is increased, compared to the planned one, the estimate for its execution will decrease proportionally to the deviation, and in the case of decreasing it will increase. The formula for correction of evaluation performance of all task $Z$ is similar:

$$
O_{v}(Z)=\frac{\gamma}{T(Z)} \sum_{i=1}^{k}\left(2 T\left(z_{i}\right)-t\left(z_{i}\right)\right) U\left(z_{i}\right) .
$$

If the result of calculations is a fractional number, then it is rounded according to the usual rules for rounding real numbers.

Using a valuation correction, you must keep in tolerable deviation to change for corresponding parameter. For example, for the 100-point grading scale used in higher education institutions, there are separate numeric intervals to translate it into the national rating scale. These intervals can be taken as a basis at using the correction of estimate. The middle of each interval can be selected as the base grade corresponding to that interval in the national rating scale. Then the correction of estimate will be within the appropriate interval of the 100 -point scale.

Therefore, it is necessary to control the progress of each elementary task in order to exercise operational control over the educational process. To control it, we have identified two numerical parameters. One of them is the result of execution of a simple task. This parameter has discrete nature and may take one of two different numeric values, for example, 0 and 1 ("done", or "not done"). Another parameter is the time of an elementary task execution. This parameter is analog (continuous), and can take any numerical value (within the education process). If the education process is continuous, then the fixation of the time of execution of an elementary task can be reduced to the fixation of a moment that separates the execution of two consecutive elementary tasks. Below we will show how to identify (recognize) these two types of parameters and their values using an artificial neural network.

\section{Interaction of educational process participants}

The above scheme of organization of educational process can be implemented both without the use of hardware and software, and with their application. This 
scheme has the greatest effect when used in cases of considerable intensity of the educational process, its saturation with a large number of various tasks, and engaging in the execution of the educational task of several performers. This situation occurs, for example, at of laboratory work executing by a group of higher education students. In this case, the student must successfully complete several operations in a certain sequence in order to achieve a positive result. The teacher should monitor the performance of several students at once, analyze the results and evaluate the execution.

For example, executing laboratory work "Lighthouse". Its aim is to study the work, capabilities and properties of the LED, the student and the teacher must jointly perform the following actions.

a) basic knowledge actualization;

b) explanation of the theoretical material by the teacher (the principle of operation of the LED and its design, auxiliary materials and equipment), in parallel with the demonstration of the necessary actions for the task;

c) familiarization of the student with the plan of laboratory work execution (issuing the task of laboratory work);

d) executing of laboratory work by the student under the guidance of the teacher;

e) executing laboratory work by a student independently;

f) task testing and bug correction, together with the teacher;

g) assessment of the student's work by the teacher, and deciding on the need for additional explanation and repeated performance of the student's laboratory task.

During the execution of the work, students must learn both theoretical material and acquire practical skills (table 1).

Table 1. Acquired skills as a result of work.

\begin{tabular}{|c|c|c|}
\hline & Theoretical & Practical \\
\hline Science (Physics) & $\begin{array}{l}- \text { Knowledge in the } \\
\text { Electricity Section } \\
\text { - Knowledge of the } \\
\text { physical parameters of } \\
\text { devices }\end{array}$ & $\begin{array}{l}\text { - Ability to create } \\
\text { an electrical } \\
\text { circuit } \\
\text { - Ability to work } \\
\text { with electronic } \\
\text { devices } \\
\text { - Ability to } \\
\text { determine device } \\
\text { parameters }\end{array}$ \\
\hline $\begin{array}{l}\text { Technologies } \\
\text { (robotics, } \\
\text { programming) }\end{array}$ & $\begin{array}{l}\text { - Knowledge of signal } \\
\text { coding technologies } \\
\text { - Knowledge in the } \\
\text { "linear programs", } \\
\text { "cycles" } \\
\end{array}$ & $\begin{array}{l}\text { - Skills to create } \\
\text { linear programs } \\
\text { - Skills to create } \\
\text { programs with } \\
\text { cycles } \\
\end{array}$ \\
\hline $\begin{array}{l}\text { Engineering } \\
\text { (design) }\end{array}$ & $\begin{array}{l}\text { - Knowledge in the } \\
\text { section "Mechanics" }\end{array}$ & $\begin{array}{l}\text { - Creating an } \\
\text { existing structure } \\
\text { - Modeling the } \\
\text { appearance of the } \\
\text { product }\end{array}$ \\
\hline Mathematics & $\begin{array}{l}\text { - Model of electrical } \\
\text { circuit }\end{array}$ & $\begin{array}{l}- \text { Be able to } \\
\text { calculate } \\
\text { parameters }\end{array}$ \\
\hline
\end{tabular}

The scheme of interaction of all participants of laboratory work is presented in Fig. 1.

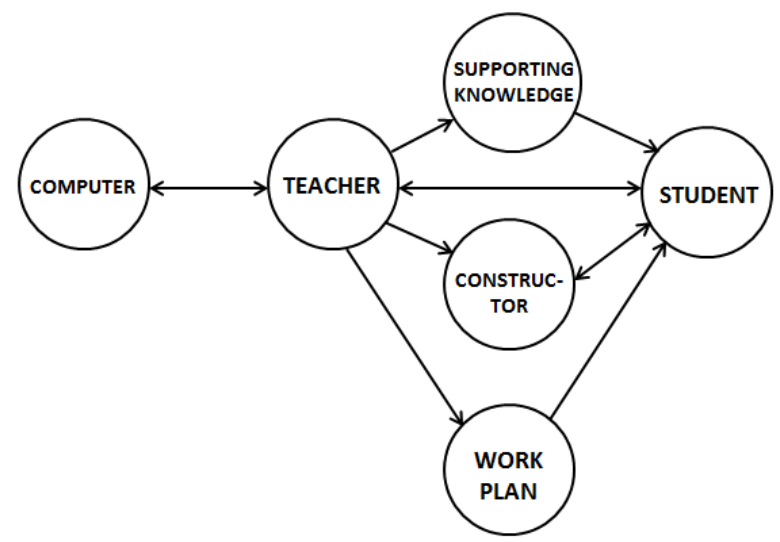

Fig. 1. The logic communication scheme at the laboratory work "Lighthouse" execution.

\section{Conclusions}

The proposed version of the method of elementary problems is quite universal. It can be applied both to individual topics of the curriculum, and to individual theoretical courses, workshops, etc. This will allow you to build a calculation of individual performance indicators in the vocational training system. Constructing of an artificial neural network to support a particular education process, certain criteria must be followed that can be controlled by the elementary task method described above. These criteria will, of course, depend on the nature, form and content of the process. They will be influenced by the goal to achieve through the education process. Before "constructing" the appropriate neural network, the teacher must clearly represent the whole education process and the desired results. For example, for the "Lighthouse (Led Blink)" laboratory work described above, the criteria can be the following: - the student should try to complete all the tasks assigned to him in due time;

- the teacher should make full use of the planned time to activate basic knowledge and to familiarize students with the necessary theoretical and technical knowledge to perform the work;

- during the stages of explanation, self-completion of elementary tasks by the student, the teacher should explain these tasks, achieve their self-fulfillment by the student.

These criteria are easily written as numerical equalities. Its execution can be controlled by an artificial neural network. They can be considered by desirable values of the outputs of the neural network, to which it must approximate the corresponding actual values of these parameters. As a rule, minimizing the deviation of the desired output values of the neural network from the actual ones is carried out by the method of least squares, minimizing the totality of the target functions drawn up for this education process.

Summarizing the above, we can conclude that the use of elements of the theory of artificial neural networks in 
combination with the method of elementary tasks makes it possible to significantly increase the efficiency of the educational process by strengthening its individualization.

\section{References}

1. G.V. Lutsenko, L.V. Kozulya, Analiz osoblyvostey vprovadzhennya problemno-oriyentovanoho navchannya u systemi vyshchoyi osvity Ukrayiny (Analysis of peculiarities of implementation of problem-oriented education in the higher education system of Ukraine). Visn. Chernihiv. nat. ped. un. Ped. Sciences. 138, 91-95 (2016)

2. V.S. Kruglyk, V.V. Osadchyi, Developing Competency in Programming among Future Software Engineers. Integration of Education 23(4), 587-606 (2019)

3. A.V. Spivakovskiy, N.A. Kushnir, N.V. Valko, M.A. Vinnyk, ICT Advanced Training of University Teachers. CEUR Workshop Proceedings 1844 (2017)

4. P.I. Fedoruk, Vykorystannya intelektual'nykh ahentiv dlya intensyfikatsiyi protsesu navchannya (Use of intelligent agents to intensify the education process). Shtuchnyy intelekt 3, 379-384 (2004)

5. R.V. Streltsov, L.V. Slavinskaya, Iskusstvennyy intellekt $v$ obrazovanii (Artificial intelligence in education). (DonNTU, Donetsk, 2010)

6. O.D. Humennyi, Kontseptsiya proektuvannya smartkompleksiv navchal'nykh dystsyplin dlya zakladiv profesiynoyi (profesiyno-tekhnichnoyi) osvity (The concept of designing smart-complexes of educational disciplines for institutions of vocational (vocational-technical) education). Teoriya i metodyka profesiynoyi osvity 2 (18), 100-112 (2018)

7. V.V. Osadchyi, V.S. Kruglik, D.O. Bukreiev, Rozrobka prohramnoho zasobu dlya prohnozuvannya vstupu abituriyentiv do zakladiv vyshchoyi osvity (Development of a software tool for predicting admission of students to higher education institutions). Ukrainian Journal of Educational Studies and Information Technology 6(3), 55-69 (2018)

8. A.G. Molibog, Programmed training: Questions of the scientific organization of pedagogical work (1967)

9. A.M. Kuh, Dissertation, National Pedagogical Dragomanov University, 2018

10. P.D. Wasserman, Neural Computing: Theory and practice (1989)

11. D.A. Gubanov, D.A. Novikov, A.G. Chkhartishvili, Sotsial'nyye seti: modeli informatsionnogo vliyaniya, upravleniya $i$ protivoborstva (Social networks: models of information influence, management and confrontation). (Publishing house of physical and mathematical literature, Moscow, 2010)

12. O. Markova, S. Semerikov, M. Popel, CoCalc as a Learning Tool for Neural Network Simulation in the Special Course "Foundations of Mathematic Informatics". CEUR Workshop Proceedings 2104, 338-403 (2018), http://ceur-ws.org/Vol2104/paper_204.pdf. Accessed 30 Nov 2018

13. S.O. Semerikov, I.O. Teplytskyi, Yu.V. Yechkalo, A.E. Kiv, Computer Simulation of Neural Networks Using Spreadsheets: The Dawn of the Age of Camelot. CEUR Workshop Proceedings 2257, 122147 (2018), http://ceur-ws.org/Vol2257/paper14.pdf. Accessed 21 Mar 2019

14. S.O. Semerikov, I.O. Teplytskyi, Yu.V. Yechkalo, O.M. Markova, V.N. Soloviev, A.E. Kiv, Computer Simulation of Neural Networks Using Spreadsheets: Dr. Anderson, Welcome Back. CEUR Workshop Proceedings 2393, 833-848 (2019), http://ceurws.org/Vol-2393/paper 348.pdf. Accessed 30 Jun 2019

15. S. Semerikov, I. Teplytskyi, Yu. Yechkalo, O. Markova, V. Soloviev, A. Kiv, Using spreadsheets as learning tools for computer simulation of neural networks. SHS Web of Conferences 75, 04018 (2020)

16. V. Osadchyi, N. Valko, L. Kuzmich, N. Abdullaeva, Studies of impact of specialized STEM training on choice further education. SHS Web of Conferences 75, 04014 (2020)

17. D. Bukreiev, Neuro-network technologies as a mean for creating individualization conditions for students learning. SHS Web of Conferences 75, 04013 (2020) 